\title{
Uma avaliação da poupança em conta corrente do governo
}

Manoel Carlos de Castro Pires*

\section{Introdução}

O instrumento de política fiscal tem vários objetivos e não é surpreendente que, ao se determinar uma meta de superávit primário, apareçam distintos grupos de interesse em discordância com o patamar estipulado. Em geral, o superávit primário deve atender interesses de curto e longo prazo. Muitas vezes os interesses de curto prazo são contraditórios entre si. Por exemplo, o superávit primário efetuado para o pagamento de juros da dívida concorre com a necessidade de melhoria dos serviços de saúde. Este conflito pode ser ainda mais problemático quando, a forma com a qual o superávit primário é gerado, implica redução dos investimentos públicos, o que cria conflito entre os objetivos de curto prazo (estabilidade) e os objetivos de longo prazo (crescimento econômico). O argumento é valido quando se nota que os testes de sustentabilidade da dívida pública mostram, em geral, que a dívida pública em relação ao PIB é sustentável no Brasil ${ }^{23}$. Entretanto, dado o atual baixo nível de investimento público, a economia brasileira tem obtido taxas de crescimento muito baixas quando comparadas com países emergentes ${ }^{24}$.

O artigo tem por objetivo avaliar o conceito de poupança em conta corrente do governo que se contrapõe ao conceito de superávit primário, pela exclusão dos investimentos públicos do cálculo deste último. Assim, objetiva-se obter níveis mais elevados de investimento público sem comprometer a estabilidade da dívida pública.

A idéia é despojada de originalidade e foi proposta por Musgrave (1939). De forma equivalente, Keynes propôs a separação do orçamento corrente e de capital conforme discutiu Kregel (1983). Mais recentemente, Blanchard \& Giavazzi (2004) defenderam esta mudança de política para os países da União Européia como forma de obter taxas de crescimento mais elevadas para este conjunto de países.

Este artigo conta com mais três seções além desta breve introdução. A seção a seguir apresenta uma aplicação do modelo $\mathrm{AK}$ ao conceito de poupança em conta corrente do

\footnotetext{
* Técnico do Instituto de Pesquisa Econômica Aplicada (IPEA) e doutorando em Economia pela Universidade de Brasília (UnB). Endereço eletrônico: manoel.pires@ipea.gov.br. O autor reconhece a contribuição de Alexandre Manoel Ângelo da Silva. Entretanto, erros e omissões são de inteira responsabilidade do autor.

${ }^{23}$ Sobre a análise de sustentabilidade para o Brasil, ver Bicalho (2005) e de Mello (2005) que verificam que a dívida pública brasileira pode ser considerada sustentável.

${ }^{24}$ Esta observação tem levado a necessidade de maior espaço fiscal para aumento dos investimentos públicos, conforme discutido em Afonso \& Biasoto (2005).
} 
governo como forma de tornar o crescimento endógeno ao investimento público. A terceira seção apresenta uma aplicação do modelo à economia brasileira e, em seguida, seguem as principais conclusões do artigo.

\section{Modelo}

$\mathrm{O}$ modelo conta com uma função de produção $Y_{t}=A K_{t}$ e com uma equação de dinâmica para a dívida pública comum nos estudos de sustentabilidade:

$$
\dot{b}=s+i^{G}+(r-n) b
$$

que afirma que a variação da dívida pública $(\dot{b})$ é função da poupança em conta corrente do governo sobre o PIB ( $s$ = gastos correntes - receitas), do investimento público em relação ao PIB e da diferença entre taxa real de juros $(r)$ e taxa real de crescimento econômico $(n)$ que incide sobre o estoque da dívida pública em relação ao PIB (b).

Uma primeira avaliação da equação (1) indica que o impacto do investimento público sobre o endividamento público é um, ou seja, o aumento de uma unidade no investimento público eleva a dívida em uma unidade.

Esta abordagem ignora os efeitos benéficos do investimento público sobre o crescimento econômico. Com efeito, suponha que o PIB (Y) possa ser descrito por um processo do tipo $A K$, onde $K$ é o estoque de capital da economia e $A$ é o fator que mantém a relação produto-capital constante. Então, desconsiderando a depreciação, obtém-se:

$$
n=\dot{K} / K=\left(I^{G}+I^{P}\right) / K=A\left(i^{G}+i^{P}\right)
$$

que mostra que o investimento público é uma das variáveis que determinam o crescimento econômico. Assim, ao substituir (2) em (1), têm-se:

$$
\dot{b}=s+i^{G}+\left(r-A\left(i^{G}+i^{P}\right)\right) b
$$

De acordo com a equação (3), o efeito do investimento público sobre o endividamento é dado por $(1-A b)$. Neste caso, se este termo for positivo, o investimento público contribui de forma positiva para a aceleração da dívida pública. Caso contrário, o investimento público desacelera a dívida pública.

Uma consideração que deve ser feita refere-se ao modo como o investimento privado é modelado. A equação (3) trata do investimento privado de forma exógena, contudo, existe relação entre o investimento público e privado. A teoria econômica afirma que se estes investimentos são realizados de forma complementar, o investimento privado reage de forma 
positiva ao investimento público e, se são concorrentes, o investimento privado reage de forma negativa ao investimento público. Desta forma, a equação (3) pode ser reescrita:

$$
\dot{b}=s+i^{G}+\left(r-A\left(i^{G}+\alpha i^{G}\right)\right) b
$$

$\operatorname{com} \alpha$ podendo ser negativo ou positivo.

Para avaliar o efeito do investimento público sobre a dívida pública, deve-se reescrever o modelo em tempo discreto e resolvê-lo recursivamente:

$$
b_{t}-b_{t-1}=s_{t}+i_{t}^{g}+(r-n) b_{t}
$$

obtendo no tempo t:

$$
b_{t}=\left(1+A i_{t}^{G}+A i_{t}^{P}-r\right)^{-1}\left(b_{t-1}+s_{t}+i_{t}^{G}\right)
$$

em t-1:

$$
b_{t-1}=\left(1+A i_{t-1}^{G}+A i_{t-1}^{P}-r\right)^{-1}\left(b_{t-2}+s_{t-1}+i_{t-1}^{G}\right)
$$

Ao realizar este procedimento $s$ vezes e substituindo em (6) obtém-se:

$$
b_{t}=\Pi_{i=o}^{t}\left(1+A i_{t-i}^{G}+A i_{t-i}^{P}-r\right)^{-1}\left(b_{0}\right)+\sum_{i=1}^{s}\left(1+A i_{t-i}^{G}+A i_{t-i}^{P}-r\right)^{-i}\left(s_{t-i+1}+i_{t-i+1}^{G}\right)
$$

Assumindo $s \rightarrow \infty$, e observando que $b_{0}=0$, o primeiro termo pode ser desconsiderado e, obtém-se:

$$
b_{t}=\sum_{t=1}^{\infty}\left(1+A i_{t-i}^{G}+A i_{t-i}^{P}-r\right)^{-t}\left(s_{t-i+1}+i_{t-i+1}^{G}\right)
$$

que mostra que a dívida pública é função da poupança em conta corrente do governo e do investimento público, ambos descontados pela produtividade do investimento público e privado dos períodos passados e pela taxa de juros, ou seja, descontada pela produtividade líquida do capital.

Assumindo que o investimento privado é função do investimento público, a equação (9) é alterada para:

$$
b_{t}=\sum_{i=1}^{\infty}\left(1+A i_{t-i}^{G}+A \alpha i_{t-i}^{G}-r\right)^{-i}\left(s_{t-i+1}+i_{t-i+1}^{G}\right)
$$

que contém implicações equivalentes à equação $(9)^{25}$.

As equações (9) e (10) mostram que a dívida pública é afetada pelo investimento público e este efeito pode ser positivo ou negativo dependendo da combinação dos parâmetros. Entretanto, observa-se que este efeito deve ser positivo para uma ampla combinação de parâmetros.

\footnotetext{
25 A literatura que estuda a relação entre investimento público e privado tem sugerido que a relação é positiva, ou seja, o investimento público cria externalidades positivas para o investimento privado. Para esta relação na economia americana, ver: Erenburg (1993) e para o Brasil, ver: Ribeiro e Teixeira (2001).
} 


\section{Análise Empírica}

A avaliação da equação (3) depende fundamentalmente do cálculo da variável $A$, que corresponde à relação produto-capital da economia brasileira. Os dados de PIB e formação bruta de capital fixo indicam que nos últimos quatro anos (Tabela 1) esta relação se situou em torno de 4,4 (média do período). Além disto, observando que a dívida líquida do setor público em 2005 se aproximou de 50\% do PIB, calcula-se que a aceleração da dívida pública ao investimento público é negativa e igual a $-1,2(1-A b)$.

Tabela 1. Cálculo da relação produto-capital - $A$

\begin{tabular}{cccc}
\hline Ano & Y (em milhões de R\$) & K (em milhões de R\$) & $A$ \\
\hline 2002 & $1.199 .144,87$ & $265.953,46$ & 4,5 \\
2003 & $1.395 .604,38$ & $307.491,07$ & 4,53 \\
2004 & $1.581 .501,25$ & $376.573,31$ & 4,19 \\
2005 & $1.728 .518,16$ & $398.597,80$ & 4,33 \\
\hline
\end{tabular}

Fonte: Ipeadata.

Para uma avaliação dos resultados obtidos a partir da equação (10), nota-se que dada à presença de inúmeras quebras estruturais na política econômica brasileira, não é adequado utilizar a equação (10) que supõe $s \rightarrow \infty$, e, portanto, é mais adequado trabalhar com (8) a qual supõe que a dívida em algum momento $t$ também explica o comportamento da própria dívida em períodos futuros.

Desta forma, a aplicação da metodologia de vetores auto-regressivos é adequada para a avaliação do modelo. A série de dívida líquida do setor público em relação ao PIB (div) foi obtida no sítio do Banco Central do Brasil. A série de investimento público do setor público consolidado (inv) tem como fonte o Tesouro Nacional, e a série de poupança em conta corrente do governo (poup) consiste da exclusão dos investimentos do superávit primário, tendo como fonte o Banco Central do Brasil. A periodicidade dos dados é de junho de 1999 a junho de 2005.

Para a aplicação empírica, é necessário testar a estacionariedade das séries. Conforme a tabela 2 que apresenta o teste $\mathrm{ADF}$ de raiz unitária das séries de investimento público, dívida e poupança em conta corrente do governo, nota-se que ambas são estacionárias em primeira diferença (I(1)). 
Tabela 2. Teste $\mathrm{ADF}$ de raiz unitária

Hipótese Nula

poup possui raiz unitária

$\mathrm{d}($ poup) possui raiz unitária

div possui raiz unitária

$\mathrm{d}($ div) possui raiz unitária

inv possui raiz unitária

$\mathrm{d}($ inv) possui raiz unitária

: Elaborado pelo autor.

Nota: A variável 'poup' foi estimada com constante; a variável dívida sem constante e sem tendência; e a variável 'inv' sem constante e sem tendência. Para esta seleção foi utilizado o critério SIC.

Os critérios de seleção do modelo (Tabela 3) indicam que o modelo mais adequado possui uma defasagem. Nota-se que os critérios de Schwarz (SIC), Akaike (AIC) e HannaQuinn (HQ) indicam o mesmo número de defasagens.

Tabela 3. Seleção do número de defasagens

\begin{tabular}{cccc}
\hline & SIC & AIC & HQ \\
\hline 1 & $1,65^{*}$ & $1,27^{*}$ & $1,43^{*}$ \\
2 & 1,97 & 1,3 & 1,57 \\
3 & 2,28 & 1,34 & 1,71 \\
4 & 2,6 & 1,37 & 1,86 \\
\hline
\end{tabular}

Com o intuito de avaliar se existe uma relação de longo prazo entre as variáveis, procedeu-se o teste de cointegração de Johansen (Tabela 4). O teste de cointegração indica que não se pode rejeitar a hipótese alternativa de ausência de relação de cointegração entre as variáveis. O teste não rejeita a hipótese nula de que existe ao menos uma relação de cointegração.

Tabela 4. Teste de Cointegração de Johansen*

\begin{tabular}{lcccc}
\hline $\begin{array}{c}\text { Hipótese Nula: } \mathbf{N}^{\mathbf{o}} \text { de } \\
\text { vetores de cointegração }\end{array}$ & Autovalor & $\begin{array}{c}\text { Estatística } \\
\text { de Traço }\end{array}$ & Valor crítico 5\% & Valor crítico 1\% \\
\hline Nenhuma** & 0,26 & 29,01 & 24,31 & 29,75 \\
No máximo 1 & 0,05 & 4,94 & 12,53 & 13,31 \\
\hline
\end{tabular}

* Sem intercepto ou tendência no vetor de cointegração.

Apesar de existir uma relação de longo prazo entre as variáveis, alguns desequilíbrios de curto prazo podem ocorrer e, portanto, a estimação do VAR deve conter um mecanismo de correção de erro com o intuito de corrigir estes desvios do equilíbrio de longo prazo. Portanto, o modelo avaliado consiste em um modelo VEC (vector error correction).

A tabela 5 mostra que a decomposição da variância indica que erros de previsão na dívida pública se devem em $99 \%$ à própria dívida pública, sendo as demais variáveis não 
significativas. No caso de erros de previsão do investimento público, $68 \%$ se devem ao próprio investimento público e $31 \%$ à poupança em conta corrente do governo, sendo os erros devido à dívida pública, não significativos. Os erros de previsão da poupança em conta corrente do governo devem-se em $2 \%$ ao superávit primário, $6 \%$ aos investimentos públicos e $90 \%$ à poupança em conta corrente.

Tabela 5. Decomposição da variância

\begin{tabular}{c|cc|c|c|c|c|c|c|c|c}
\hline \multirow{2}{*}{ Mês } & \multicolumn{3}{|c|}{ div } & \multicolumn{3}{c|}{ inv } & \multicolumn{3}{c}{ poup } \\
\cline { 2 - 9 } & div & inv & poup & div & inv & poup & div & inv & poup \\
\hline 1 & 100 & 0,00 & 0,00 & 0,00 & 83,04 & 16,95 & 0,41 & 0,00 & 99,58 \\
2 & 99,52 & 0,22 & 0,24 & 0,04 & 84,20 & 15,75 & 1,57 & 0,10 & 98,32 \\
3 & 99,40 & 0,33 & 0,26 & 0,08 & 83,51 & 16,40 & 1,80 & 0,39 & 97,79 \\
4 & 99,31 & 0,39 & 0,28 & 0,11 & 82,13 & 17,74 & 2,00 & 0,82 & 97,17 \\
5 & 99,28 & 0,43 & 0,28 & 0,14 & 80,46 & 19,39 & 2,14 & 1,36 & 96,48 \\
6 & 99,26 & 0,45 & 0,27 & 0,16 & 78,65 & 21,18 & 2,26 & 1,99 & 95,73 \\
7 & 99,26 & 0,45 & 0,27 & 0,17 & 76,79 & 23,02 & 2,36 & 2,69 & 94,93 \\
8 & 99,27 & 0,46 & 0,27 & 0,19 & 74,93 & 24,86 & 2,45 & 3,43 & 94,11 \\
9 & 99,28 & 0,45 & 0,26 & 0,20 & 73,11 & 26,67 & 2,53 & 4,19 & 93,26 \\
10 & 99,29 & 0,45 & 0,25 & 0,22 & 71,34 & 28,43 & 2,61 & 4,97 & 92,41 \\
11 & 99,31 & 0,44 & 0,24 & 0,23 & 69,63 & 30,12 & 2,67 & 5,75 & 91,56 \\
12 & 99,32 & 0,43 & 0,23 & 0,24 & 68,00 & 31,75 & 2,73 & 6,53 & 90,72 \\
\hline
\end{tabular}

Fonte: elaboração a partir dos dados da pesquisa.

As funções de impulso resposta (Figura 1) mostram que choques transmitidos sobre as próprias variáveis possuem efeitos positivos e não se dispersam ao longo de dez meses. A dívida pública responde de forma positiva e permanente ao impulso no investimento público, e de forma negativa e permanente ao impulso na poupança em conta corrente do governo.

A resposta do investimento público ao impulso na dívida pública é negativa e não se dissipa ao longo de dez meses. Em relação ao impulso na poupança em conta corrente do governo, o investimento público reage de forma positiva e permanente. A resposta da poupança em conta corrente do governo é positiva ao impulso na dívida pública e não se dissipa ao longo de dez meses. A poupança em conta corrente do governo reage de forma positiva e permanente ao impulso no investimento público. 
Figura 1. Funções de impulso resposta

Resposta à Inovação de um D.P.
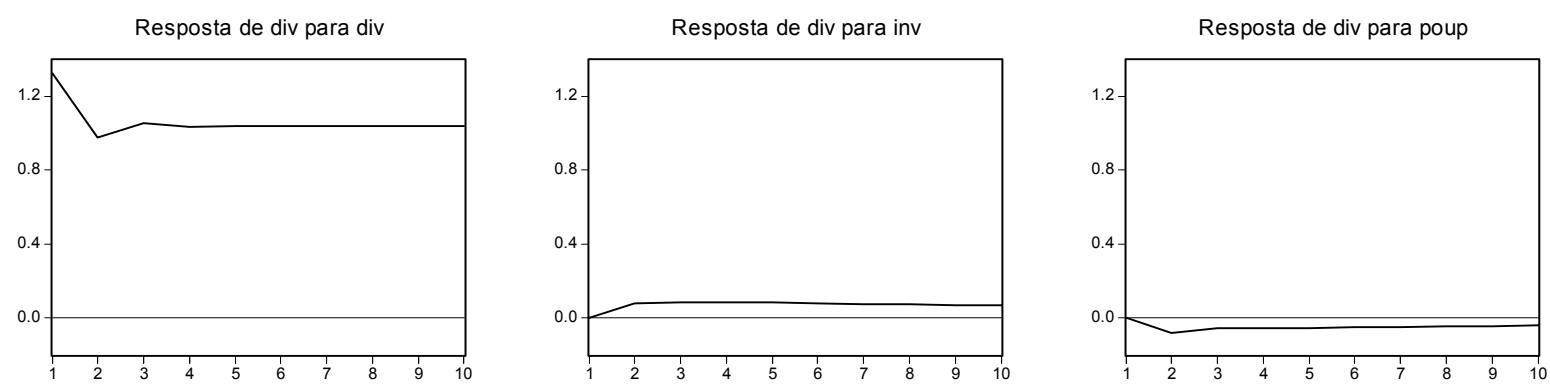

Resposta de inv para div

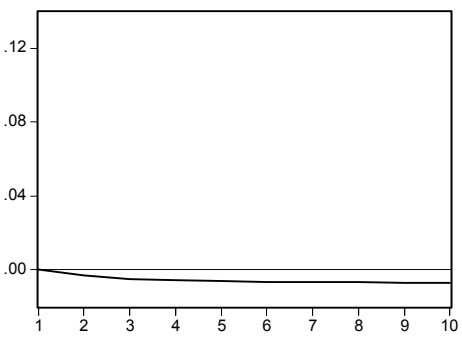

Resposta de inv para inv

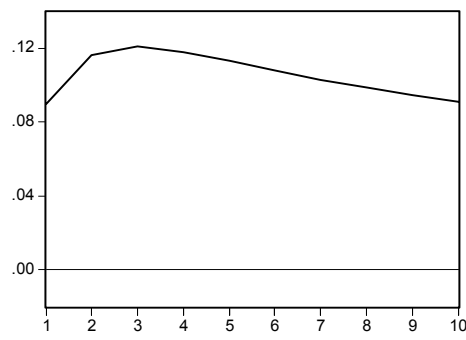

Resposta de inv para poup

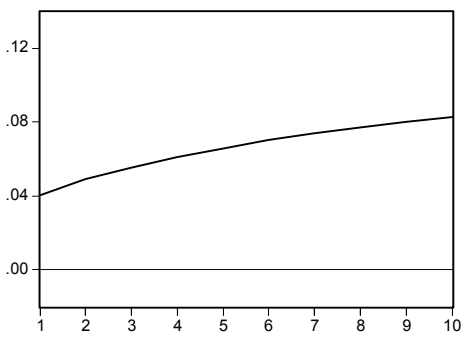

Resposta de poup para div
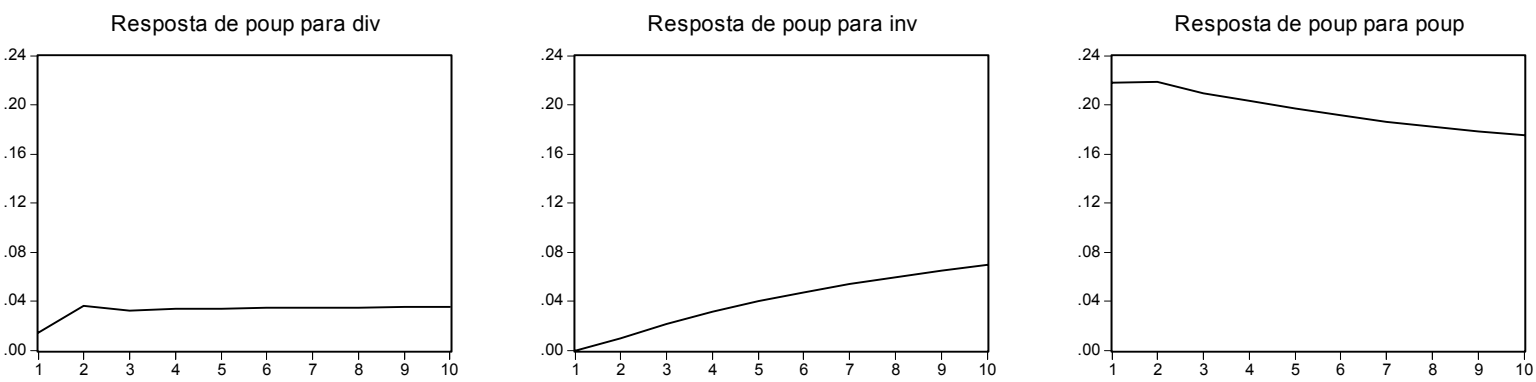

\section{Conclusões}

O artigo teve como objetivo avaliar a proposta de adoção da poupança em conta corrente do governo como meta de política fiscal. A poupança em conta corrente do governo difere do conceito de superávit primário pela exclusão dos investimentos públicos.

Os resultados do artigo mostraram que a adoção da poupança em conta corrente pode contribuir para a desaceleração da dívida pública em relação ao PIB, devido ao efeito positivo que possui sobre o crescimento econômico. Assim, esta é uma estratégia que pode contribuir na estabilização macroeconômica, pois pode reduzir a aceleração da dívida, ao passo que eleva o crescimento econômico aumentando o bem-estar social.

O impacto desta estratégia sobre o nível da dívida foi avaliado a partir de um modelo de correção de erro (VEC) que indicou um pequeno efeito positivo do aumento do 
investimento público sobre a dívida e um pequeno efeito negativo da poupança em conta corrente sobre a dívida, o que sugere uma estratégia adequada do ponto de vista de sustentabilidade da dívida. Ressalta-se que, além de não implicar elevação substancial na relação dívida-PIB, obtém-se elevação da taxa de crescimento econômico aumentando o bemestar social.

\section{Referências Bibliográficas}

AFONSO, J. R., AMORIM, E., BIASOTO JR., G. "Fiscal space and public sector investments in infrastructure: a Brazilian case-study". Ipea, 2005 (Texto para Discussão, 1.141).

BICALHO, A. (2005). "Teste de Sustentabilidade e Ajuste Fiscal no Brasil Pós-Real." Fundação Getúlio Vargas, EPGE, dissertação de mestrado.

BLANCHARD, O. J. \& GIAVAZZI, F. (2004). "Improving the SGP through a proper accounting of public investment." Discussion Paper Series, n 4.220, Centre for Economic Policy Research.

DE MELLO, L. (2005). "Estimating a Fiscal Reaction Function: The Case of Debt Sustainability in Brazil." OECD Economics Department Working Paper, n. 423, OECD, Paris.

ERENBURG, S. J. (1993). "The Real Effects of Public Investment on Private Investment". Applied Economics, vol. 25, 831-837.

KREGEL, J. (1983). “Budget Deficits, Stabilisation Policy and Liquidity Preference: Keynes's Post-War Policy Proposals.” In: F. Vicarelli (ed.), Keynes's Relevance Today. The Macmillan Press: London.

MUSGRAVE, R. A. (1939). "The nature of budgetary balance and the case for the capital budget”. American Economic Review, 29, 260-271.

RIBEIRO, M. B. \& TEIXEIRA, J. R. (2001). “An Econometric Analysis of Private Sector Investment in Brazil”. Cepal Review, vol. 74, august. 